\title{
Water Retention Characteristics of Porous Ceramics Produced from Waste Diatomite and Coal Fly Ash
}

\author{
Kae-Long Lin and Ju-Ying Lan
}

\begin{abstract}
This study examines potential waste diatomite and coal fly ash reuse to prepare water absorption and retain porous ceramics. The operating conditions are constant pressure (5 MPa), sintering temperature $\left(1000-1270^{\circ} \mathrm{C}\right)$, sintering time $(2 \mathrm{~h})$, waste diatomite containing coal fly ash at different proportions $(0-20 \%)$, respectively. The porous ceramic samples containing coal fly ash show low thermal conductivity properties $(0.278-0.349 \mathrm{~W} / \mathrm{mK})$, probably owing to the more pores than those in the concrete $(1.458 \mathrm{~W} / \mathrm{mK})$. Water release (t1/2 value) by the porous ceramic samples is decelerated by porous ceramic samples containing coal fly ash, due to the synergy effect of high water absorption by the coal fly ash and better than in the foamed glass material $(4 \mathrm{~h})$. Porous ceramic samples containing coal fly ash is highly promising for use in water absorption and retention applications.
\end{abstract}

Index Terms - Coal fly ash, compressive strength, diatomite, porous ceramics.

\section{INTRODUCTION}

At present, around 1.8 million tonnes of diatomaceous earth are mined worldwide annually [1]. Diatomaceous earth is an attractive and suitable material for fabricating porous ceramics because of its' low cost, well-defined porosity, low density and high thermal stability [2]. The chemical composition and physical structure of diatomite give it great commercial value for a wide range of applications, including beer filter aids, the removal of textile dyes from waste water [3], [4] and the sorption of heavy metal ions [5], [6]. Small diatomite particles with high porosity can be used in the fabrication of highly permeable microporous membrane filters [7]. Clearly, low-grade materials require purification but whether that purification is sufficient as diatomite obtained with a high specific surface area and impurities have an inferior porous micro-structure after sintering. Macroporous ceramics combine high permeability with favorable mechanical, thermal and chemical stability, and are therefore attractive for a wide range of industrial applications [1]-[8].

The amount of electricity consumed in Taiwan has been increased. This trend has resulted in a drastic increase in coal demand for use in coal-fired electric power stations, owing to a relatively stable supply of coal and a surge in petroleum prices. In Taiwan, coal ash emissions, which include fly ash, cinder ash, and clinker ash, amounted to approximately $5,060,000$ tonnes in 2011. Coal fly ash (CFA), generally

Manuscript received October 26, 2012; revised January 18, 2013.

Kae-Long Lin and Ju-Ying Lan are with the Department of Environmental Engineering, National I-Lan University, I-Lan, Taiwan (e-mail: kllin@niu.edu.tw, doris tension@hotmail.com) collected by electrostatic precipitators, constitutes about $90 \%$ of all solid residues [9].Its major constituents are $\mathrm{SiO}_{2}, \mathrm{Al}_{2} \mathrm{O}_{3}$ and $\mathrm{Fe}_{2} \mathrm{O}_{3}$, and its minor constituents include $\mathrm{CaO}, \mathrm{MgO}$ and other oxides. Coal fly ash is used to manufacture brick [10], fly ash mineral-based polymer composites [11], ceramic tableware and artware [12]. Recent investigations have demonstrated alternative means of managing coal fly ash in glass [13] and ceramic tiles [14]-[16]. However, little research as been done on the use of coal fly ash in the production of porous ceramics. According to Sheng [17], coal fly ash with large amounts of glass network formers $\left(\mathrm{SiO}_{2}+\mathrm{Al}_{2} \mathrm{O}_{3}\right)$ can be utilized to fabricate durable products. Sanitary landfills are commonly used to dispose of coal fly ash, but rapid urbanization has made locating suitable landfill sites increasingly difficult. Increasing demand for natural resources and a scarcity of environmentally acceptable solid waste disposal sites are motivating numerous municipalities in Taiwan to consider resource recovery as an alternative.

Porous ceramics with well-defined macroscopic shapes and high mechanical stability can be fabricated using novel processing route, while retaining the intrinsic porosity of the porous powder from which they are manufactured [17], [18]. Sintering is a thermal process that transforms a compact powder into a bulk material, and is used in mass-producing complex-shaped components. Sintering is a complex process of microstructural evolution, which involves bond formation, neck growth, pore channel closure, pore shrinkage, densification, coarsening, and grain growth. The features and properties of the porous ceramic material, for example, porosity, pore size distribution, pore morphology, and pore connectivity (commonly identified as the relationship between open and closed porosity), depended strongly on the composition and processing method.

Rising temperatures in large cities poses an increasing environmental threat, especially during the summer in Taiwan. This predicament arises from the increasing amount of heat generated by human activity (e.g., vehicles and air conditioners) and the increasing amount of surface areas covered by artificial materials with a high solar absorption capacity. This global warming phenomenon is referred to as the "heat island effect" [19]. Water absorption and retention of porous ceramics as building materials are characterized by their permanence, heat insulation [20] and water retention. This study demonstrates the feasibility of producing water absorption and retention of porous ceramic monoliths from diatomite and coal fly ash. The ability to use diatomite and coal fly ash produced as water absorption and retention of porous ceramic is also examined by studying their water retention and thermal conductivity properties. 


\section{MATERIAL AND METHODS}

\section{A. Materials}

The waste diatomite and coal fly ash used were collected from the food-processing industry and thermal power plants located in Taipei County, Taiwan. In total, $500 \mathrm{~kg}$ of waste diatomite and coal fly ash were obtained from the food-processing industry and thermal power plants, respectively. The waste diatomite and coal fly ash were pulverized using a ball mill until they could pass through a 100 mesh $(0.149 \mathrm{~mm})$ sieve. The resultant pulverized waste diatomite and coal fly ash were then stored in a desiccator until testing.

\section{B. Preparation of Compacted Sintered Porous Ceramics Samples}

The waste diatomite and the coal fly ash samples were oven-dried at $105^{\circ} \mathrm{C}$ for $24 \mathrm{~h}$ and ground in a ball mill to form fine powders (until pass through a 100 mesh sieve) suitable for pressing. The powder samples were mixed with each other to prepare a known mass percentage of coal fly ash in diatomite in different concentration of coal fly ash ( $0-20 \%$ by mass) to produce porous ceramics samples. The content of the coal fly ash in the waste diatomite mixture was varied from $0 \%$ to $20 \%$ by mass. The samples were compacted at 5 $\mathrm{MPa}$ to form cylinder specimens $(51.8 \mathrm{~mm}(\Phi) \times 15 \mathrm{~mm}(\mathrm{H}))$ that were then desiccated before testing. The compacted porous ceramic specimens were placed on a platinum plate and burnt in an electrically heated furnace using a ramp rate of $5^{\circ} \mathrm{C} \mathrm{min}-1$. The porous ceramic samples were then sintered at temperatures between $1000^{\circ} \mathrm{C}$ and $1270^{\circ} \mathrm{C}$ for 120 minutes. The sintered samples were then cooled to room temperature and stored in a desiccator for subsequent physical properties testing and microstructure analyses.

\section{Characterization of Sintered Porous Ceramics Specimens}

The chemical composition and physical characteristics of the porous ceramic pellets and sintered products were analyzed. The porous ceramic samples were digested using $\mathrm{HNO}_{3} / \mathrm{HClO}_{4} / \mathrm{HF}$ according to NIEA R355.00C and then analyzed with Inductively Coupled Plasma Atomic Emission Spectroscopy (ICP-AES) for the major elements [21]. Sample mechanical quality was obtained by performing crushing strength tests. In this test, an oven-dried sample was placed in a steel cylinder with an internal diameter of 51.8 $\mathrm{mm}$ and a height of $15 \mathrm{~mm}$. The samples were filled into the cylinder up to an upper incision mark. The cylinder was covered and pressed down using a steel puncheon until the upper level of the porous ceramic sample was reduced by a prescribed distance. The crushing strength value was calculated as the ratio between the load and the cross-sectional area of the cylinder in stress units. The weight loss and absorption capacities were measured using the NIEA R204.00T [22] method and ASTM C556 [23], respectively.

Unconfined compressive strength (ASTM C39-72): Three specimens were used for the compressive strength tests while the fourth one was used for the microstructure examination.

A quick thermal conductivity meter based on ASTM C 1113-90 hot-wire method was used (ASTM C 1113-90) [24].

Water absorption of the porous ceramic samples was determined by immersing them in water at $20^{\circ} \mathrm{C}$ and weighing after predetermined time intervals up to $24 \mathrm{~h}$. The water absorbed after $24 \mathrm{~h}$ was defined as the water absorption (Wa (\%)). Release of the absorbed water was evaluated in an atmosphere with the relative humidity controlled at 55\% using a saturated $\mathrm{Mg}\left(\mathrm{NO}_{3}\right) 2.6 \mathrm{H}_{2} \mathrm{O}$ solution. The water release rate was then evaluated from the time at which half the absorbed water was lost $\left(\mathrm{t}_{1 / 2}(\mathrm{~h})\right)$ [25].

\section{RESULTS AND DISCUSSION}

\section{A. Characteristics of Waste Diatomite and the Coal Fly Ash}

The densities of the waste diatomite and the coal fly ash were 1.26 and $1.58 \mathrm{~g} \mathrm{~cm}^{-3}$, respectively. The $\mathrm{pH}$ of the waste diatomite and the coal fly ash were 7.21 and 8.93, respectively. Table I show chemical composition of the waste diatomite and coal fly ash, respectively. The chemical composition of waste diatomite and the coal fly ash were shown in Table I.

TABLE I: CHEMICAL COMPOSITION OF THE WASTE DIATOMITE AND COAL FLY ASH

\begin{tabular}{ccc}
\hline \hline Chemical Composition & Waste Diatomite & Coal Fly Ash \\
\hline $\mathrm{SiO}_{2}(\%)$ & $93.6 \pm 0.13$ & $47.41 \pm 0.35$ \\
$\mathrm{Al}_{2} \mathrm{O}_{3}(\%)$ & $1.08 \pm 0.23$ & $19.78 \pm 0.23$ \\
$\mathrm{Fe}_{2} \mathrm{O}_{3}(\%)$ & $0.87 \pm 0.25$ & $7.73 \pm 0.20$ \\
$\mathrm{CaO}(\%)$ & $0.20 \pm 0.01$ & $16.51 \pm 0.03$ \\
$\mathrm{MgO}(\%)$ & - & $4.02 \pm 0.02$ \\
$\mathrm{SO}_{3}(\%)$ & $0.04 \pm 0.03$ & - \\
$\mathrm{K}_{2} \mathrm{O}(\%)$ & $0.19 \pm 0.23$ & $1.32 \pm 0.01$ \\
\hline \hline
\end{tabular}

\section{B. Mechanical Characteristics of Porous Ceramics}

Table II shows the open porosity of the pure diatomite specimens that were fired at various temperatures. The porosity declined slowly from $1000{ }^{\circ} \mathrm{C}$ to $1270{ }^{\circ} \mathrm{C}$ (from $64.02 \%$ to $61.27 \%$ ). However, the rate of change was not constant. The high porosity was attributed to the unique porous mineralogical character of diatomite that contained $20 \%$ coal fly ash, the porosity of which did not change considerably during sintering. First, the open porosity declined gradually from $60.3 \%$ at $1000{ }^{\circ} \mathrm{C}$ to $58.9 \%$ at $1100{ }^{\circ} \mathrm{C}$. In the second stage, the porosity decreased from $54.6 \%$ at $1200{ }^{\circ} \mathrm{C}$ to $52.7 \%$ at $1270{ }^{\circ} \mathrm{C}$, and the rate of decline was higher than that in the first stage. In this stage, sintering reduced the volume, and most of the pores were closed. This indicated a simpler morphology that was attributed to a mass diffusion transfer and pure sintering shrinkage [25].

The water absorption rate, which is the weight of the moisture in the pores as a fraction of the weight of the sintered specimen, is an effective index of the quality of porous ceramics. Table II shows the results of the water absorption tests on various coal fly ash -diatomite mixtures that were heated at four temperatures. Water absorption increased from $75.9 \%$ to $93.4 \%, 74.1 \%$ to $91.1 \%, 67.3 \%$ to $87.9 \%$, and $63.4 \%$ to $85.2 \%$, with heating temperatures of $1000{ }^{\circ} \mathrm{C}, 1100{ }^{\circ} \mathrm{C}, 1200{ }^{\circ} \mathrm{C}$, and $1270{ }^{\circ} \mathrm{C}$, respectively. The results show that, as the coal fly ash content declined, the water absorption of the porous ceramic samples increased. We observed a near-linear dependence of water absorption 
on the coal fly ash contents (from 10 to $20 \mathrm{wt}$. \%) in the samples of diatomite that contained coal fly ash. Furthermore, the amount of water absorbed by the porous ceramics decreased with an increase in the heating temperature. The decline in the rate of water absorption with increasing heating temperature $\left(1200{ }^{\circ} \mathrm{C}\right)$ suggests that local liquid-phase sintering occurred, which contributed to a decrease in pore volume and the water absorption rate. Water absorption of the materials in this study is consistent with the trend that was first described by Furlani et al. [25]; that is, the sintering behavior of ceramics is affected by the formation of a " transitory liquid" phase, which improves the densification of the sintered samples. The bonding capacity of the mixture is related to the amount of the coal fly ash added to the mixture.

The compressive strength is the crucial index of the engineering quality of porous ceramic material. Table II shows the compressive strength test results for porous ceramics made from diatomite and coal fly ash mixtures. The compressive strength of the porous ceramics increased when the heating temperature increased from $1000{ }^{\circ} \mathrm{C}$ to $1270{ }^{\circ} \mathrm{C}$. The results showed that the optimal heating temperature that maximized the compressive strength was $1270{ }^{\circ} \mathrm{C}$. The compressive strength of the mixed porous ceramic samples of diatomite that contained the coal fly ash decreased slightly when the heating temperature increased above $1200{ }^{\circ} \mathrm{C}$. The porous diatomite ceramic strength decreased when up to $20 \%$ of the coal fly ash was added to the porous ceramics that were heated to $1200{ }^{\circ} \mathrm{C}$. The coal fly ash can be converted into porous ceramics by using this method. Consequently, the coal fly ash can be blended with diatomite to produce porous ceramics.

TABLE II: MECHANICAL CHARACTERISTICS OF POROUS CERAMICS

\begin{tabular}{|c|c|c|c|c|c|c|}
\hline \multirow{2}{*}{$\begin{array}{c}\text { Mechanic } \\
\text { Characteristic }\end{array}$} & \multirow{2}{*}{$\begin{array}{c}\text { Heating } \\
\text { Temperature } \\
\left({ }^{\circ} \mathrm{C}\right) \\
\end{array}$} & \multicolumn{5}{|c|}{ Coal Fly Ash Replacement Level (\%) } \\
\hline & & 0 & 5 & 10 & 15 & 20 \\
\hline \multirow{4}{*}{$\begin{array}{c}\text { Porosity } \\
(\%)\end{array}$} & 1000 & 64.02 & 62.14 & 61.86 & 61.63 & 60.23 \\
\hline & 1100 & 63.41 & 61.29 & 60.49 & 59.69 & 58.95 \\
\hline & 1200 & 62.59 & 59.97 & 57.51 & 56.01 & 54.61 \\
\hline & 1270 & 61.27 & 57.23 & 55.07 & 53.83 & 51.71 \\
\hline \multirow{4}{*}{$\begin{array}{c}\text { Water } \\
\text { absorption }(\%)\end{array}$} & 1000 & 93.39 & 88.08 & 84.72 & 81.65 & 75.91 \\
\hline & 1100 & 91.13 & 83.83 & 80.59 & 77.79 & 74.12 \\
\hline & 1200 & 87.85 & 80.60 & 75.04 & 71.36 & 67.34 \\
\hline & 1270 & 85.23 & 75.83 & 70.92 & 67.43 & 63.44 \\
\hline \multirow{4}{*}{$\begin{array}{l}\text { Compressive } \\
\text { strength } \\
(\mathrm{MPa})\end{array}$} & 1000 & 2.48 & 3.29 & 3.89 & 4.39 & 4.89 \\
\hline & 1100 & 4.36 & 5.55 & 6.48 & 7.20 & 8.17 \\
\hline & 1200 & 5.92 & 8.10 & 11.25 & 13.65 & 16.31 \\
\hline & 1270 & 6.10 & 9.67 & 12.77 & 15.38 & 17.04 \\
\hline
\end{tabular}

\section{Thermal Conductivity of Porous Ceramic Samples}

Fig. 1 shows the variation in thermal conductivity of waste diatomite containing coal fly ash sintered porous ceramic samples at various temperatures. When the heating temperature was increased from $1000{ }^{\circ} \mathrm{C}$ to $1200{ }^{\circ} \mathrm{C}$, the thermal conductivity of the waste diatomite sintered porous ceramics was $0.277,0.279,0.280$, and $0.282 \mathrm{~W} / \mathrm{mK}$. Additionally, the thermal conductivity of porous ceramic samples increased with the heating temperature. When the amount of coal fly ash was increased from $5 \%$ to $20 \%$, the thermal conductivity of the sintered porous ceramics was $0.322-0.439,0.359-0.469,0.398-0.559$, and $0.419-0.580 \mathrm{~W} /$ $\mathrm{mK}$. Moreover, the thermal conductivity of the porous ceramic samples increased with the coal fly ash content. This increase was attributed to the porous structure of sintered porous ceramic samples containing coal fly ash, resulting in a denser structure. In addition, the thermal conductivity decreased because of the decreasing density of the sintered porous ceramic samples, which subsequently increased the void content. The samples revealed a correlation between the density and thermal conductivity for sintered porous ceramic samples, in which the thermal conductivity increased with the density. In this study, the porous ceramic samples had a thermal conductivity of approximately $0.278-0.580 \mathrm{~W} / \mathrm{mK}$, which was lower than that for the concrete $(1.458 \mathrm{~W} / \mathrm{mK})$. The porous ceramic samples exhibited properties of low thermal conductivity, which may be attributed to the larger number of pores compared to those in the concrete.

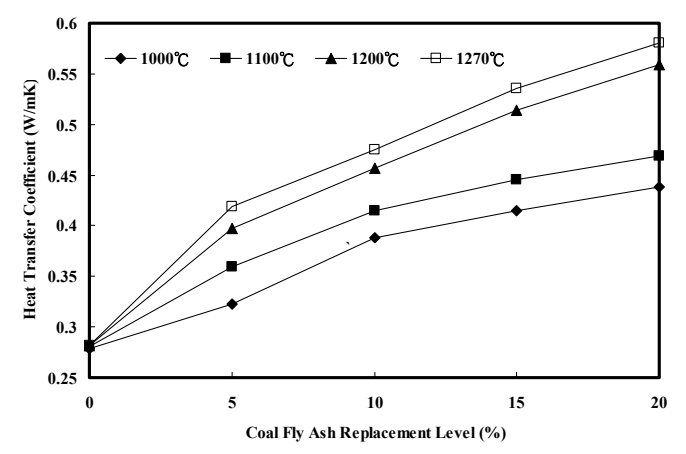

Fig. 1. Thermal conductivity of porous ceramics.

\section{Water-Retention Properties of Porous Ceramic Samples}

The water-release parameter $\left(t_{1 / 2}\right)$ was defined by the time required for half of the amount of water to be released from the samples. Fig. 2 shows the $t_{1 / 2}$ values as a function of the Coal Fly Ash content of the samples. The $t_{1 / 2}$ values are low, with $50 \%$ of the Wa retained for $48 \mathrm{~h}$ in the porous ceramic samples containing coal fly ash samples at a relative humidity of $55 \%$ at $20{ }^{\circ} \mathrm{C}$; this value is lower than that in pure diatomite porous ceramic samples when the heating temperature reached $1000{ }^{\circ} \mathrm{C}$. Increasing the heating temperature from $1000{ }^{\circ} \mathrm{C}$ to $1200{ }^{\circ} \mathrm{C}$ decreased the water-retention properties of the resulting porous ceramic samples containing coal fly ash samples. When the heating temperature reached $1000{ }^{\circ} \mathrm{C}$, the porous ceramic samples containing $20 \%$ coal fly ash had $\mathrm{t}_{1 / 2}$ values of approximately $11 \mathrm{~h}$; these values were larger than those for the porous ceramic samples containing $5 \%$ of the coal fly ash $(8 \mathrm{~h})$. Because the $t_{1 / 2}$ value of the foamed glass sample was approximately $4 \mathrm{~h}$, the porous ceramic samples containing the coal fly ash exhibited excellent slow water-releasing properties, which may be attributed to the smaller pores, compared to those in the foamed glass. The large amounts of coal fly ash in the porous ceramic samples also facilitated a slow water release, which yielded acceptable water-retention properties. These properties make the porous ceramic samples containing coal fly ash samples promising for use as water-retaining materials to combat "heat island" effects. 

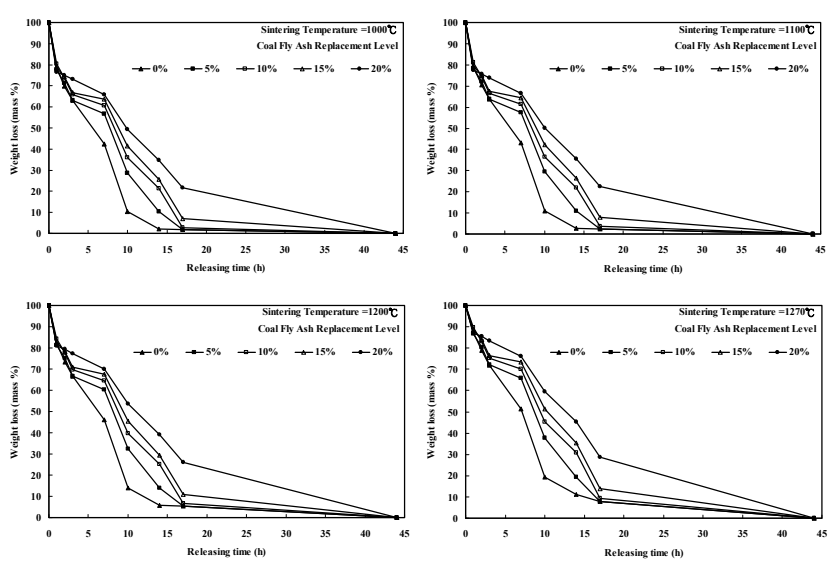

Fig. 2. Water-retention properties of waste diatomite containing coal fly ash sintered porous ceramics samples at various temperatures.

\section{E. Distribution of Sizes and Total Volume of Pores in Ceramics}

Fig. 3 plots mercury intrusion data obtained upon heating to $1100^{\circ} \mathrm{C}$. Fig. 3 (a) includes one strong peak with a range of pore sizes of approximately $1.5-2.5 \mu \mathrm{m}$, and a smaller peak at $0.1-1 \mu \mathrm{m}$. The pores with sizes of $1.5-2.5 \mu \mathrm{m}$ are linked to the voids among the powder particles, while those with sizes of around $0.1-1 \mu \mathrm{m}$ are the pores that are inherent to diatomite porous ceramics samples Fig. 4 (a). The main peak shifts to a smaller pore size as the heating temperature increases. Fig. 4 plots the mercury intrusion data obtained upon heating to $1200^{\circ} \mathrm{C}$. Fig. 4 (a) includes one strong peak at pore sizes of around 1.5-3 $\mu \mathrm{m}$, and a smaller peak at $0.2-1$ $\mu \mathrm{m}$. Fig. 5 plots mercury intrusion data obtained upon heating to $1270^{\circ} \mathrm{C}$. Fig. 5 (a) includes a strong peak at pore sizes of approximately 2-6 $\mu \mathrm{m}$, and a smaller peak around 0.8- $1.5 \mu \mathrm{m}$. Accordingly, the sizes of the interparticle pores decrease as the peak temperature increases, and the interparticle voids become partially filled with the melt and/or collapse.
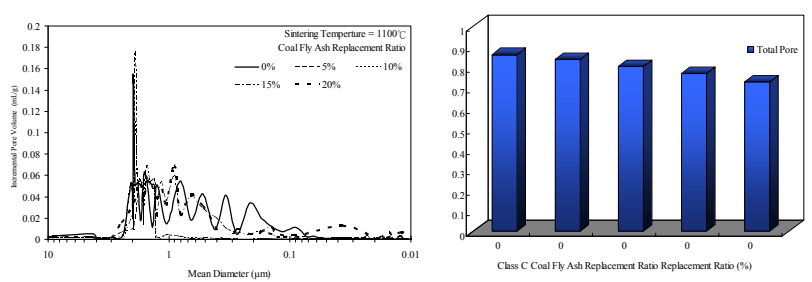

Fig. 3. Distribution of sizes and total volume of pores in ceramics of porous ceramics sintered at $1100^{\circ} \mathrm{C}$ (a) Distribution of sizes, (b) total volume of pores.
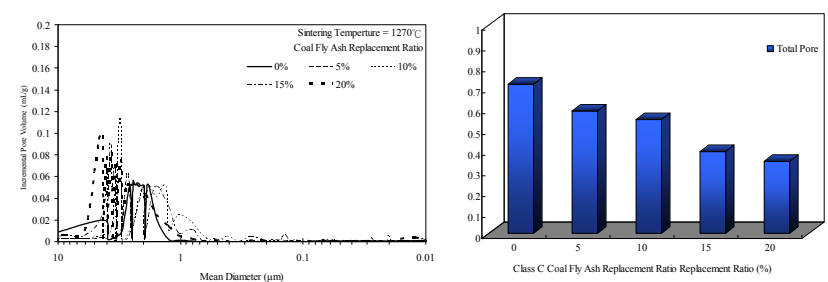

Fig. 4. Distribution of sizes and total volume of pores in ceramics of porous ceramics sintered at $1200^{\circ} \mathrm{C}$ (a) Distribution of sizes, (b) total volume of pores.

Fig. 3 - Fig. 5 (b) display the evolution of the porosity of sintered bodies that contained coal fly ash. They plot, the cumulative volume of pores against pore size. The sintered samples that were prepared from diatomite that contained more coal fly ash had smaller pores. The figures demonstrate

that the porous diatomite ceramics samples had a greater volume of pores. However, for both types of sample, the dependence of total volume on coal fly ash content is strongest between 15 and 20 wt. \% Fig. 3-Fig. 5 (b). Fig. 3 Fig. 5 (b) present the evolution of relevant morphological parameters, such as total $\mathrm{Hg}$ intrusion volume (porosity) and average size of interconnecting pores such as the pore necks among the particles of the coal fly ash in the samples with coal fly ash contents from 10 to $20 \mathrm{wt}$ \%. However, as the concentration of coal fly ash increases, the coal fly ash begins to interact with particle and an open structure that interconnects the fine pores is slowly formed. As expected, porosity and average pore size values depend directly on the coal fly ash content. Increasing the amount of coal fly ash particles tends to reduce the average distance between diatomite particles in samples that contain coal fly ash, and make the diffusion mechanism during sintering more effective.
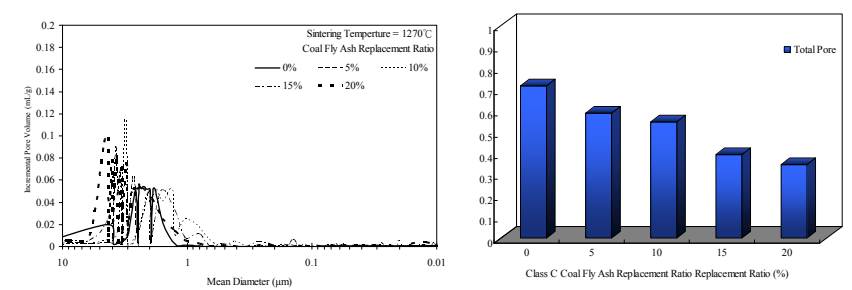

Fig. 5. Distribution of sizes and total volume of pores in ceramics of porous ceramics sintered at $1270^{\circ} \mathrm{C}$ (a) Distribution of sizes,(b) total volume of pores.

\section{F. Scanning Electron Microscopic Microphotographs of Porous Ceramics}

Fig. 6 shows the SEM microphotographs of porous ceramic samples sintered at $1270{ }^{\circ} \mathrm{C}$. Fig. 6 (a) shows that a small fraction of the diatomite powder began to melt, the liquid phase accumulated in regions with a negative curvature, and the contact points between pairs of particles formed necks.

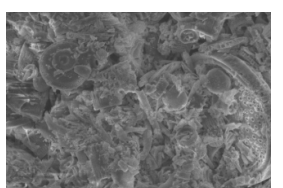

(a) $0 \%$

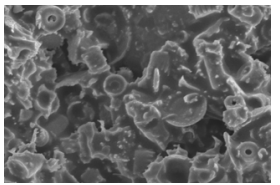

(d) $15 \%$

Fig. 6. SEM microphotographs of porous ceramics samples.

The initially isolated diatomite particles were converted into an integral body, which contained numerous closed pores. A microstructural change was observed during sintering below $1270^{\circ} \mathrm{C}$. Cylindrical diatomite particles were identified easily, and a number of micropores were distributed. Scanning electron microscopic measurements revealed the coal fly ash in various proportions in the microstructures of porous ceramics Figs. 6(b)-Fig. 6(e). The coal fly ash bonded the diatomite powder into relatively strong monoliths. However, a melt phase covered the diatomite particles and filled the diatomite pores when the sintering temperature was increased to $1270{ }^{\circ} \mathrm{C}$. Impurities in diatomite, such as $\mathrm{K}_{2} \mathrm{O}, \mathrm{CaO}$, and $\mathrm{MgO}$, favor the formation 
of low-temperature eutectics and the subsequent formation of a melt phase in the silica-rich grains. The internal pore volume of diatomite that contained $20 \%$ of the coal fly ash was not reduced substantially after heating to $1270{ }^{\circ} \mathrm{C}$ Fig. 6 (e). Slight fusion occurred at the particle contact points at $1270{ }^{\circ} \mathrm{C}$. The powder partially melted, and both the interparticle pores and the internal structure collapsed.

\section{CONCLUSIONS}

This study examined potential waste diatomite and coal fly ash reuse in the preparation of water absorption and retention of porous ceramics. The porous ceramics fabricated from waste material exhibited enhanced water absorption and retention capabilities. Moreover, the results of this study also indicated that water absorption and retention are dependent on the pore structures. These structures revealed a correlation between the density and thermal conductivity for sintered porous ceramic samples, in which thermal conductivity increases with density. The porous ceramic samples containing the coal fly ash exhibited low thermal conductivity properties, which may be attributed to the larger number of pores than those in the concrete. Additionally, water release $\left(t_{1 / 2}\right.$ value) by the porous ceramic samples was decelerated using porous ceramic samples containing the coal fly ash because of the synergy effect of high water absorption by the coal fly ash. The $t_{1 / 2}$ values of the porous ceramic samples were higher than those in the foamed glass material. In summary, porous ceramic samples containing the coal fly ash have excellent mechanical properties, making them feasible for use in water absorption and retention of porous ceramic applications.

\section{ACKNOWLEDGMENT}

The authors would like to thank the National Science Council of the Republic of China, Taiwan, for financially supporting this research under Contract No. NSC 101-2221-E-197-010-MY3.

\section{REFERENCES}

[1] H. Hadjar, B. Hamdi, M. Jaber, J. Brendlé, Z. Kessaïssia, H. Balard, and J. B. Donnet, "Elaboration and characterization of new mesoporous materials from diatomite and charcoal," Micropor. Mesopor. Mater., vol. 107, pp. 219-226, 2008

[2] S. Martinovic, M. Vlahhovic, T. Boljanac, and L. Pavlovic, "Preparation of filter aids based on diatomites," Int. J. Miner. Process., vol. 80 , no. 2-4, pp. $255-260,2006$

[3] Z. Al-Qodah, W. K. Lafi, Z. Al-Anber, M. Al-Shannag, and A. Harahsheh,"Adsorption of methylene blue by acid and heat treated diatomaceous silica.Desalination," vol. 217 , no. 1-3, pp.212-214, 2007.

[4] M. A. Al-Ghouti, M. A. M. Khraisheh, M. N. Ahmad, and S. J. Allen, "Microcolumn studies of dye adsorption onto manganese oxides modified diatomite," J. Hazard. Mater, vol. 146, no. 1-2, pp. 316-327, 2007.

[5] A. E. Osmanlioglu, "Natural diatomite process for removal of radioactivity from liquid waste," J. App. Rad. Isotopes., vol. 65, no. 1, pp. 17-20, 2007.

[6] P. V. Vasconcelos, J. A. Labrincha, and J. M. F. Ferreira, "Permeability of diatomite layers processed by different colloidal techniques," J. Eur. Ceram. Soc., vol. 20, pp. 201-207, 2000.

[7] F. Akhtar, P. O. Vasiliev, and L. Bergstrom, "Hierarchically porous ceramics from diatomite powders by pulsed current processing," J. Am. Ceram. Soc., vol. 92, no. 2, pp. 338-343, 2009.

[8] D. J. Green and P.Colombo, "Cellular ceramics: intriguing structures, novel properties, and innovative applications," MRS Bull., vol. 28, no. 4, pp. 296-300, 2003.
[9] S. Kashiwakura, T. Takahashi, H. Maekawa, and T. Nagasaka "Application of 11B MAS-NMR to the characterization of boron in coal fly ash generated from Nantun coal," Fuel., vol. 89, pp. 1006-1011, 2010.

[10] E .E. Berry, R. T. Hemmings, and B.J. Cornelius, "Mechanism of hydration reactions in high volume fly ash pastes and mortars," Cem. Concr. Comp., vol. 12, pp. 253-261, 1990.

[11] J. Paya, J. Monzo, M.V. Borrachero, E. Peris-Mora, E. and Gonzales-Lopez, "Mechanical treatment of fly ashes. Part II. Particle morphologies in ground fly ash (GFA) and workability of GFA-Cement mortars," Cem. Concr. Res., vol. 26, pp. 225-235, 1996.

[12] M. Anderson, "A new low-cost PFA brick making process. International Conference on Ash Technology," London, pp. 569-573, 1984.

[13] X. Wu, J. Wastiels, S. Faignet, and P. Bauweraerts, "A composite matrix material based on fly ash, in: A.M. Brandt, V.C. Li, I.H. Marshall (Eds.), in: Proceedings on International Symposium on Brittle Matrix Composites 4," IKE and Woodhead Publ, Warsaw, 437-446.

[14] S. K. Mukherji, and B. B. Machhoya, "The utilisation on fly-ash in the preparation of ceramic tableware and artware." British Ceram. Trans., vol. 92, no. 1, pp. 6-12, 1993.

[15] J. Sheng, B. X. Huang, J. Zhang, H. Zhang, J. Sheng, and S. Zhang, "Production of glass from coal fly ash," Fuel, vol. 82, pp. 181-185, 2003.

[16] C. Leroy, M. C. Ferro, R. C. C. Monteiro, and M. H. V. Fernandes, "Production of glass-ceramics from coal fly ash," Fuel, vol. 21, pp. 195-202, 2001.

[17] L. Barbieri, I. Lancellotti, T. Manfredini, I. Queralt, M. J. Rincon, and M. Romero, "Design, obtainment and properties of glasses and glassceramics from coal fly ash," Fuel, vol. 78, pp. 271-276, 1999.

[18] A. Olgun, Y. Erdogan, Y. Ayhan, and B. Zeybek, "Development of ceramic tiles from coal fly ash and tincal ore waste," Ceram. Int., vol. 31 , pp. $153-158,2005$.

[19] J. Sheng, "Vitrification of borate waste from nuclear power plant using coal fly ash. (I) Glass formulation development," Fuel, vol. 80, pp. $1365-1369,2001$.

[20] P. Dibandjo, L. Bois, C. Estournes, B. Durand, and P.Miele, "Silica, carbon and boron nitride monoliths with hierarchical porosity prepared by spark plasma sintering process," Micropor. Mesopor. Mat., vol. 111 no. $1-3$, pp. $643-648,2008$,

[21] F. Wakai, G. G. Diego, and D. R. Arturo, "Pore channel closure in sintering of a ring of three spheres," J. Euro. Ceram. Soc. vol. 27, pp. 3365-3370, 2007.

[22] V. Tikare, M. Braginsky, E. A. Olevsky, "Numerical simulation of solidstate sintering. I. Sintering of three particles," J. Am. Ceram. Soc., vol. 86, pp. 49-53, 2003.

[23] K. Okada, A. Ooyama, T. Isobe, and Y. Kameshima, A. Nakajima, and K. J. D.MacKenzie, "Water retention properties of porous geopolymers for use in cooling applications," J. Euro. Ceram. Soc., vol. 29, pp. 1917-1923, 2009.

[24] T. Kato, K. Ohashi, M. Fuji, and M. Takahashi, "Water absorption and retention of porous ceramics fabricated by waste resources," J. Ceram. Soc. Japan. vol. 116, no. 2, pp. 212-215, 2008.

[25] F. Akhtar, Y. Rehman, and L. Bergström, "A study of the sintering of diatomaceous earth to produce porous ceramic monoliths with bimodal porosity and high strength," Powder Technolo. vol. 201, no. 3, pp. 253-257, 2010.

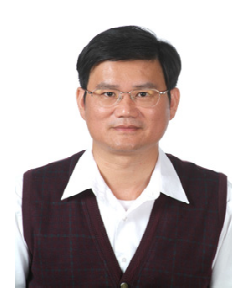

Kae-Long Lin is a professor in Department of Environmental Engineering National Ilan University, Taiwan, 26047, Republic of China. To pursue a research career in Pozzolanic reaction/ Eco-cement/ Waste Treatment/Management/ recycle/ E-waste recycle.

He is now in Department of Environmental Engineering, National Ilan University, Taiwan.

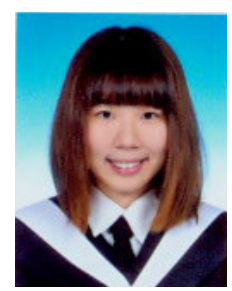

Ju-Ying Lan received the B.S. degree in environmental engineering from National I-Lan University, I-Lan, Taiwan, in 2007. She is currently a master student in Deapertment of Environmental Engineering National Ilan University, Taiwan. 